\title{
Lihasikojen hännänpurenta on sikapaikan tuottoa laskeva monisyinen ongelma
}

\author{
Alina Sinisalo ja Jarkko Niemi \\ MTT Taloustutkimus, Luutnantintie 13,00410Helsinki,alina.sinisalo@mtt.fi ja jarkko.niemi@mtt.fi
}

\section{Tiivistelmä}

Sikojen hännänpurenta on monisyinen ongelma. Suomessa on havaittu hännänpurentajälkiä tai muita häntävaurioita 10-30 \%:lla sioista. Purentaa voi esiintyä kaikenikäisillä sioilla. Hännänpurentaongelma voi alkaa jo porsaan kasvatusvaiheessa, lihasikavaiheessa ja sitä voidaan havaita myös lähes teuraspainoisilla sioilla.

Hännänpurenta on sian stressin aiheuttama käytöshäiriö. Sen taustalla voi olla useita syitä. Useimmat sikojen hyvinvointiin vaikuttavat tekijät, kuten virikkeiden määrä, sikojen yleinen terveydentila, lattiarakenne ja ruokinta vaikuttavat hännänpurennan esiintymiseen. Hännänpurenta saattaa puhjeta, kun tuotannossa tai eläinten elinolosuhteissa tapahtuu häiritsevä äkillinen muutos. Stressitekijöitä voi myös esiintyä tilalla, mutta hännänpurentaa ei havaita. Hännänpurennan laukaisevista tekijöistä ei tiedetä vielä tarpeeksi, joten lisätutkimuksia tarvitaan.

Purenta aiheuttaa kärsimystä sialle ja taloudellisia menetyksiä kasvattajalle. Menetykset syntyvät heikentyneen kasvun ja rehumuuntosuhteen, hoitokulujen, teurastamohylkäysten ja eläinten kuolemantapausten takia. Hännänpurenta aiheuttaa kipuja ja heikentää sian yleistä terveydentilaa. Hännänpurenta on syynä infektioon ja lihantarkastushylkäyksiin monissa tapauksessa.

Tässä tutkimuksessa selvitetään lihasikojen hännänpurennan taustasyitä sekä purentaongelman taloudellista merkitystä lihasikalassa. Taustasyitä selvitetään aikaisempia tutkimuksia hyödyntäen. Taloudellista merkitystä selvitetään stokastisella dynaamisella simulointimallilla, joka kuvaa hännänpurentaongelman kehittymisen karsinassa. Esitetyllä lähestymistavalla voidaan tarkastella hännänpurennan ja sen ennaltaehkäisyn taloudellista merkitystä sekä arvioida ennaltaehkäisyn ja hoidon taloudellisuutta.

Hännänpurennan taloudellisia vaikutuksia arvioitiin esimerkkisimulaatiomalleilla. Säännöllisesti esiintyessään hännänpurennan vaikutus sikapaikan keskituottoon voi olla useita euroja. Havaittiin, että karsinatasolla purennan aiheuttamiin taloudellisiin menetyksiin vaikuttaa olennaisesti purennan esiintyvyys, sen aiheuttaman kasvuhäiriön kesto, ruhohylkäysten määrä, lääkityksen tarve sekä tuottajan toiminta ensimmäisen purennan jälkeen lisätapausten ehkäisemiseksi. Jos purentaa esiintyy esimerkkitapauksessa $51 \%$ :ssa karsinoista, mutta esiintyvyys pystytään ennaltaehkäisyn keinoin vähentämään $41 \%:$ iin karsinoista, silloin hännänpurennan pitkällä aikavälillä aiheuttama menetys ilman tehostetusta ennaltaehkäisystä aiheutuvia lisäkustannuksia vähenee 4,8 eurosta 2,6 euroon sikapaikkaa ja vuotta kohti. Vähentämällä sikojen hännänpurentaa voidaan parantaa eläinten hyvinvointia ja lihasikatalouden kilpailukykyä Suomessa.

Asiasanat: lihasika, hännänpurenta, hyvinvointi, kustannukset, simulointimalli 


\section{Johdanto}

Hännänpurenta on merkittävä lihasikojen hyvinvointiongelma Suomessa ja monissa muissa maissa. Suomessa teuraslinjoilla tehdyissä tutkimuksissa havaittiin häntävaurioita 10-30 prosentilla sioista. Purentaa voi esiintyä kaikenikäisillä sioilla. Hännänpurentaongelma voi alkaa jo porsaan kasvatusvaiheessa, lihasikavaiheessa ja sitä voidaan havaita myös lähes teuraspainoisilla sioilla, joskin 2-3 viimeisen kasvatusviikon aikana purennan esiintyminen on yleensä vähäistä.

Hännänpurenta on sian stressin aiheuttama käytöshäiriö. Kirjallisuudesta ei saa yksiselitteisiä vastauksia sikojen hännänpurennan alkamiselle, mutta erilaisia riskitekijöitä tunnistetaan $(\mathrm{mm}$. Bracke ym. 2004, EFSA 2007). Hännänpurennan taustalla voi olla useita syitä. Tämän tutkimuksen alkuvaiheessa selvitettiin hännänpurennan taustasyitä kirjallisuuskatsauksen avulla. Tutkimuksessa käytettiin myös laajaa aineistoa Suomen sianjalostus Oy:n Längelmäen kantakoeasemalta.

Olkien tarjoaminen virikkeeksi sioille esiintyy usein keinona vähentää hännänpurentaa (Hunter ym. 2001, Day ym. 2002, Paul ym. 2007, Zonderland ym. 2008) ja olkien puutetta pidetään merkittävänä purentariskiä lisäävänä tekijänä. Tutkimusten mukaan tuotantorakennuksen lämpötila ja ilmanvaihtoratkaisut sekä ruokintajärjestelmä vaikuttavat hännänpurennan esiintyvyyteen (Hunter ym. 2001, Lindertz 2005, Paul ym. 2007). Ruokintaan liittyviä epäkohtia, kuten ruokintalaitteiden häiriöitä, ruokintapisteiden vähäistä määrää, rehun suolapitoisuuden vaihtelua tai rehun väärää koostumusta sekä liemiruokintaa pidetään merkittävinä hännänpurennan riskiä lisäävinä tekijöinä (Guise ja Penny 1998, Hunter ym. 2001, Moinard ym. 2003). Karsinan lattian ominaisuuksien on myös todettu vaikuttavan purennan esiintyvyyteen. Lindertzin (2005) mukaan mitä enemmän karsinassa on ritilälattiaa, sitä enemmän esiintyy hännänpurentaa. Englantilaisessa tutkimuksessa (Breuer ym. 2005) havaittiin viitteitä myös siitä, että taipumus purra muita sikoja olisi jossain määrin perinnöllistä. Myös sukupuolten erilainen käyttäytyminen vaikuttaa purennan esiintyvyyteen (Wallgren ja Lindahl 1996, Hunter ym. 2001, Valros ym. 2004). Lisäksi purrut siat kasvavat yleensä heikommin (Wallgren ja Lindahl 1996) ja niillä esiintyy enemmän tulehduksia sekä ruhohylkäyksiä kuin puremattomilla sioilla (Huey 1996, Valros ym. 2004, Kritas ja Morrison 2007). Myös tämän tutkimuksen tulokset tukevat sukupuolen vaikutusta purentariskiin ja sitä, että purenta heikentää sian kasvua ja rehumuuntosuhdetta. On kuitenkin mahdollista, että hännänpurentaa ei havaita vaikka riskitekijöitä esiintyykin. Hännänpurennan laukaisevista tekijöistä ei tiedetä vielä tarpeeksi, joten lisätutkimuksia tarvitaan.

Hännänpurenta aiheuttaa sioille kärsimystä ja taloudellisia menetyksiä niiden kasvattajille. Häntävauriot heikentävät sikojen yleistä terveydentilaa. Lisäksi hännänpurentaongelma aiheuttaa tuottajille stressiä, lisätyötä ja -kuluja. Mittavia menetyksiä aiheuttavat muun muassa kokoruhohylkäykset ja tapaukset, joissa sika kuolee. Tämän tutkimuksen tavoitteena on kehittää malli, jolla voidaan tarkastella hännänpurennan ja sen ennaltaehkäisyn taloudellista merkitystä. Tutkimusmenetelmänä käytetään dynaamista stokastista simulointia. Malli kuvaa sikojen kasvun karsinassa perustuen Niemen (2006) ja Niemen ja Sevón-Aimosen (2009) esittämiin kasvumalleihin, sekä purennan esiintymisen ja sen vaikutukset karsinassa. Malli laskee sikapaikan tuottoarvon erilaisilla purennan esiintyvyystasoilla. Kehitetyllä mallilla voidaan jatkossa arvioida ennaltaehkäisyn ja hoidon taloudellisuutta sekä ratkaista päätössääntöjä sille, missä olosuhteissa ja miten paljon ennaltaehkäisyyn kannattaa panostaa.

\section{Aineisto ja menetelmät Aineisto ja sen tarkastelu}

Tutkimusta varten tehtiin laaja kirjallisuuskatsaus, josta poimittiin tietoja simulointimallia varten. Mallin tunnuslukujen valinnassa hyödynnettiin myös Suomen sianjalostus Oy:n Längelmäen kantakoeasemalta saatua aineistoa ja siitä laskettuja tunnuslukuja. Aineisto sisältää runsaasti mittaustietoa 6812 siasta, kuten eläimen saapumis- ja lähtöpäivät, sukupuoli, karsinnan tunniste, sian perinnöllinen taso (jalostusarvot), oire- ja hoitotiedot, lääkitykset, poistot. Kattavimmat tiedot ovat noin 3000 siasta.

Aineistosta saadaan tietoa muun muassa hännänpurennan alkamisesta, sen vaikutuksesta sian kasvuun, syömiseen ja rehunkulutukseen sekä teuraslaatuun. Aineiston avulla voidaan seurata hännänpurijoita takautuvasti niin, että voidaan tunnistaa sellaiset yksilöpiirteet, jotka altistavat hännänpurennalle tai ovat merkkejä sen alkamiselle, kuten yksilöllinen kasvu, syöntikäyttäytyminen, sian sukupuoli tai koko. Aineisto sisältää tietoja yksittäisistä sioista, joten niistä voitiin koostaa dynamiikka, jota tarvitaan purennan mallintamiseksi karsinassa esiintyvänä epidemiana sen jälkeen kun ensimmäinen purentatapaus havaitaan. 
Aineistoa tarkasteltiin vertailemalla purijoiden ja muiden sikojen keskiarvoja sekä purennan uhrien ja muiden sikojen keskiarvoja sukupuolittain vertailemalla, sekä näiden ryhmien välisiä eroja tilastollisesti testaamalla. Purennan esiintymistä ajoitusta tarkasteltiin laskemalla purennan esiintymiskerralle (karsinassa purentatapaus $n$ ) ehdollisia todennäköisyyksiä. Lisäksi laskettiin kahden peräkkäisen samassa karsinassa esiintyvän purennan välisen ajan jakauma.

\section{Malli}

Tutkimuksessa käytetään dynaamista stokastista mallia. Malli perustuu Niemen (2006) esittämään dynaamiseen kasvumalliin ja sen päälle tehtyyn Monte Carlo -simulointimalliin, joka mukailee Niemen ja Sevón-Aimonen (2009) esittämää lähestymistapaa. Malli toimii Matlab-ohjelmistossa ja sitä voidaan käyttää simulointityökaluna. Mallilla voidaan simuloida sian kasvua ja purentaa karsinassa yksilötasolla kuitenkin huomioiden karsinan sikojen tasalaatuisuus ja purennan esiintyvyys. Mallissa on myös mahdollisuus optimoida hännänpurentaa ennaltaehkäisevien toimenpiteiden taloudellisuus.

Malli kuvaa sikojen kasvua karsinassa hyödyntäen Niemen (2006) ja Niemen ja Sevón-Aimosen (2009) esittämiä malleja. Kehitetyssä mallissa ruokintaan ja perimään liittyvät muuttujat ovat vakioituja. Sian elopaino hetkellä $t$ lasketaan sian ruhossa olevan rasva- $\left(x_{t, L}\right)$ ja valkuaiskomponentin $\left(x_{t, P}\right)$ painon mukaan ja elopainon kasvu mallinnetaan komponenttien kasvujen avulla (ks. Niemi 2006). Sian joutumista purennan uhriksi kuvataan binaarimuuttujalla $\left(x_{t, B}\right)$. Perimää kuvaavat tunnusluvut kuvataan matriisissa $\mathbf{x}_{t, G}$. Kasvut kuvataan siirtymäyhtälöillä $g$ :

$$
\begin{aligned}
& x_{t+1, L}=\mathrm{g}\left(x_{t, L}, x_{t, P}, x_{t, B}, \mathbf{x}_{t, G}, u_{t, E}, u_{t, P}\right), \quad t=1, \ldots, T \mathrm{ja} \\
& x_{t+1, P}=\mathrm{g}\left(x_{t, L}, x_{t, P}, x_{t, B}, \mathbf{x}_{t, G}, u_{t, E}, u_{t, P}\right), \quad t=1, \ldots, T,
\end{aligned}
$$

(kaava 1)

(kaava 2)

joissa $t$ on ajanhetkeä kuvaava päiväindeksi, $u_{t, E}$ on karsinan sioille päivänä $t$ rehussa annetun energian määrä ja $u_{t, P}$ on karsinan sioille päivänä $t$ rehussa annetun valkuaisen määrä.

Hännänpurennan todennäköisyyttä kuvaava siirtymäyhtälö on muotoa:

$$
\mathrm{P}\left(x_{t+1, B}=1\right)=\mathrm{g}\left(t, x_{t, B}, x_{t, K}\right),
$$

jossa $x_{t, K}$ on samassa kasvatuserässä ja karsinassa hetkeen $t$ mennessä purtujen sikojen yhteismäärä. Mikäli sika joutuu purennan uhriksi hetkellä $t$, binaarimuuttujan $x_{t, B}$ arvo muuttuu nollasta yhdeksi ja sian kasvun oletetaan heikkenevän $11 \%$ (vrt. Wallgren ja Lindahl 1996). Koska purentaa esiintyy kasvatuksen eri vaiheissa, tämä tarkoittaa runsaan $5 \%$ heikennystä keskipäiväkasvussa. Tämän lisäksi purennan oletetaan lisäävän ruhohylkäyksiä (Valros ym. 2004). Kullekin sialle määritetään perinnölliset kasvukäyrän tunnusluvut (Niemi 2006). Tunnuslukujen keskiarvo on tunnettu. Yksittäisen sian tunnusluvut ovat stokastisia.

Sikojen teurastus perustuu päätössääntöön, joka mukaan nopeimmin kasvavat siat teurastetaan niiden saavuttaessa ns. kärkipainovälin ylimmän painon, joka on tässä tapauksessa $90 \mathrm{~kg}$, ja kaikki loput siat, hitaimmin kasvavien sikojen keskipaino ylittää kärkipainovälin alarajan, joka on tässä tapauksessa $75 \mathrm{~kg}$. Sianlihan hintana käytettiin $1,45 € / \mathrm{kg}$, porsaan hintana $56 € / \mathrm{kpl}$, ohran hintana $116 € / \mathrm{t}$ ja soijarouheen hintana $350 € /$ t. Purentatapauksen hoitokustannuksena on käytetty noin $6 € /$ tapaus.

\section{Tulokset ja tulosten tarkastelu \\ Purtu vs. ei-purtu sika}

Purrulla sialla tarkoitetaan sikaa, jolle oli merkitty aineistossa oireeksi "häntää syöty". Purijalla tarkoitetaan sikaa, jolle oli merkitty oireeksi "puree muiden häntiä". Aineiston 6812 havainnosta purtuja sikoja oli 756 (11,1\% sioista) ja purijoita 33 (0,5\% sioista). Hännänpurentaa oli havaittu joillakin sioilla useampana päivänä. Karjuja oli purtu eniten (14,6 \% karjuista) ja imisiä oli purtu enemmän kuin leikkoja (11,3\% imisistä ja 8,3 \% leikoista). Aineiston mukaan karjut purevat muiden sikojen häntiä useammin kuin leikot tai imisät. Purijasiat olivat aineistossa keskimäärin 1,9 kg kevyempiä kuin muut siat. Muita merkitseviä eroja ei havaittu purijoiden ja purtujen välillä.

Tutkimusaineisto viittaa siihen, että purtujen sikojen keskimääräinen päiväkasvu on heikompi kuin puremattomien sikojen keskipäiväkasvu ja eroa olisi havaittavissa myös sukupuolten välillä. Purrut siat näyttävät kuitenkin olevan perinnölliseltä tasoltaan hieman heikommin kasvavia kuin puremat- 
tomat siat. Puremattomien sikojen silava ja lihas ovat paksumpia kuin purruilla sioilla. Sen sijaan purtujen sikojen lihaprosentti on suurempi kuin puremattomien sikojen. Lihaprosenttien erot saattavat johtua sian kasvun hidastumisesta, sillä ylläpitoon tarvittavan rehun osuus (per teurastettu sika) syödystä rehusta voi lisääntyä kasvun hidastuessa ja lihaprosentin tiedetään laskevan sian teuraspainon noustessa.

Selvimpiä eroja näyttäisi olevan sikojen poistoissa. Purennan uhriksi joutuneita sikoja on jouduttu poistamaan noin kolminkertainen määrä verrattuna puremattomiin sikoihin. Poistetuilla sioilla on muun muassa keskimäärin heikompi päiväkasvu kuin poistamattomilla sioilla. Kuolleisuudessa ei ole havaittu merkitsevää eroa, vaikka tutkimuksissa on viitteitä siihen, että purruilla sioilla kuolleisuus olisi suurempi kuin ei-purruilla sioilla (Sambraus 1985, Fraser ja Broom 1997). Syynä voi olla se, että sikalassa on käytäntönä hoitaa purennat ja reagoida purentatapauksiin.

\section{Purennan ajoitus ja dynamiikka}

Tulokset viittaavat siihen, että uuden purennan todennäköisyys karsinassa on sitä suurempi mitä enemmän purentatapauksia karsinassa havaitaan saman kasvatuserän aikana. Noin $42 \%$ karsinoista kärsii vähintään yhdestä purennasta. Toisen purennan esiintymisen todennäköisyys (uuden purennan todennäköisyys, kun ensimmäinen tapaus on havaittu) on aineistossa noin $61 \%$ ja kolmannen ja neljännen purennan esiintymisen todennäköisyys (uuden purennan todennäköisyys, kun toinen tai kolmas tapaus on havaittu) on aineistossa noin $71 \%$.

Purentojen välinen aika lyhenee purentojen määrän kasvaessa (kuva 1). Karsinan ensimmäinen purentahavainto jakautuu melko tasaisesti 65 ensimmäiselle sikalaan tulon jälkeiselle päivälle. Karsinan toinen purenta havaitaan $45 \%$ :ssa tapauksista samana päivänä kuin ensimmäinen purenta, ja karsinan kolmas purenta havaitaan $49 \%$ :ssa tapauksista samana päivänä (14 päivän kuluessa) kuin toinen purenta. Kun tarkastellaan purentojen pääjoukkoa, $90 \%$ :ssa tapauksista karsinan toinen purenta havaitaan 19 päivän kuluessa ensimmäisestä purennasta, ja $90 \%$ :ssa tapauksista karsinan kolmas purenta 14 päivän kuluessa toisesta purennasta.

Kun edellä mainittu purennan ehdollisen todennäköisyyden kehitys ja tieto purentojen välisestä ajasta yhdistetään, voidaan simuloida purentailmiön kehitys karsinassa. Tulokset viittaavat siihen, että purennasta kärsivien karsinoiden lukumäärän noustessa purennan esiintyvyys sikalassa kasvaa aluksi hitaasti, mutta karsinakohtaisen esiintyvyyden ylittäessä $40 \%$ purennan esiintyvyys nousee nopeasti (kuva 2).

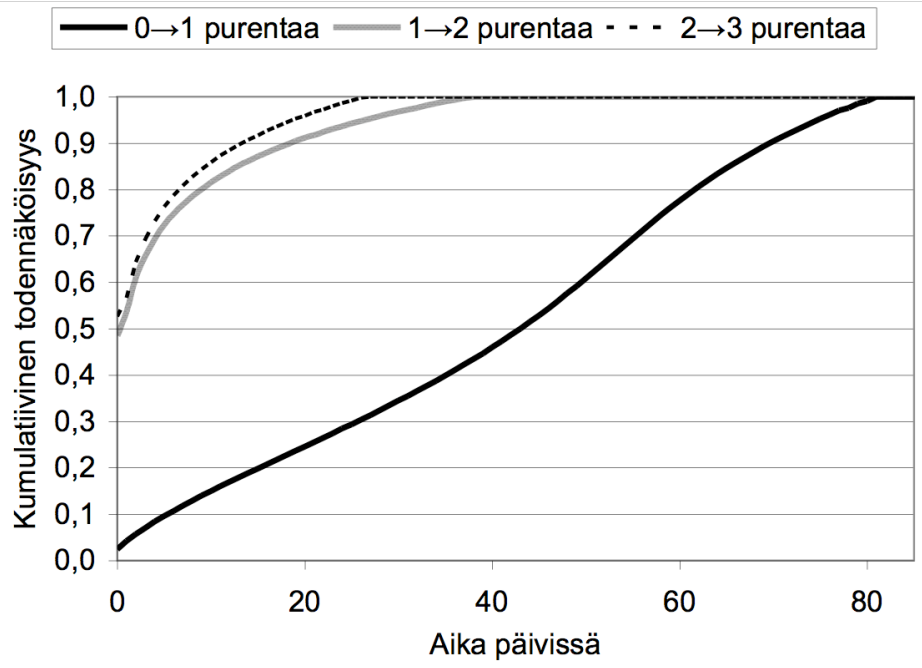

Kuva 1. Ensimmäisen purennan havaitsemispäivien jakautuminen alkaen koetilalle tulosta karsinassa, sekä ensimmäisen ja toisen ja toisen ja kolmannen välisen purennan välisen ajan jakautuminen silloin kun kyseinen purenta esiintyy karsinassa. 


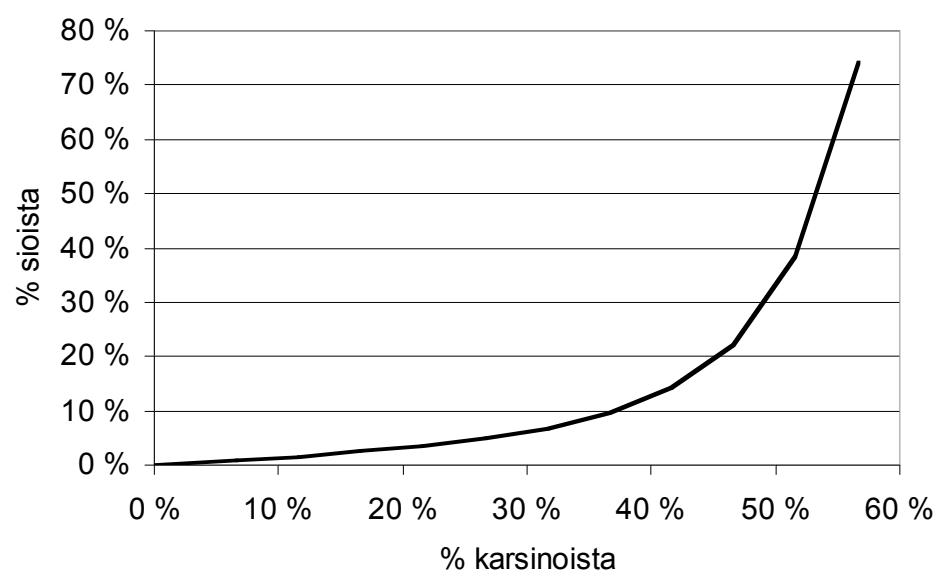

Kuva 2. Simuloitu karsinakohtaisen (\%:ssa karsinoista purentaa) ja sikakohtaisen (\%:a sioista purtu) hännänpurennan esiintyvyyden välinen yhteys.

\section{Purennan vaikutus sikapaikan tuottoon}

Aineiston ja kehitetyn simulointimallin avulla tarkasteltiin purennan käyttäytymistä ja purentariskin aiheuttamia menetyksiä valitussa esimerkkitapauksessa. Purennan todennäköisyyden kasvu karsinnoissa lisää sikapaikkatuoton vuotuisia menetyksiä (kuva 3).

Karsinatason tarkastelu paljastaa, että on tärkeää ennaltaehkäistä purentaa ja puuttua havaittuihin purentatapauksiin nopeasti. Kun purennasta kärsivien karsinoiden osuus sikalan kaikista karsinoista nousee, purentaepidemia todennäköisyys kasvaa ja sikalan taloudellinen tuotto voi heiketä purentariskin vuoksi nopeasti. Jos purentaa esiintyy esimerkiksi 51\%:ssa karsinoista, mutta esiintyvyys pystytään ennaltaehkäisyn keinoin vähentämään $41 \%$ :iin karsinoista, silloin hännänpurennan pitkällä aikavälillä aiheuttama menetys ilman tehostetusta ennaltaehkäisystä aiheutuvia lisäkustannuksia vähenee 4,8 eurosta 2,6 euroon sikapaikkaa ja vuotta kohti. Esimerkiksi 500 lihasikapaikan sikalassa tämä tarkoittaa yli tuhannen euron lisätuottoa vuodessa.

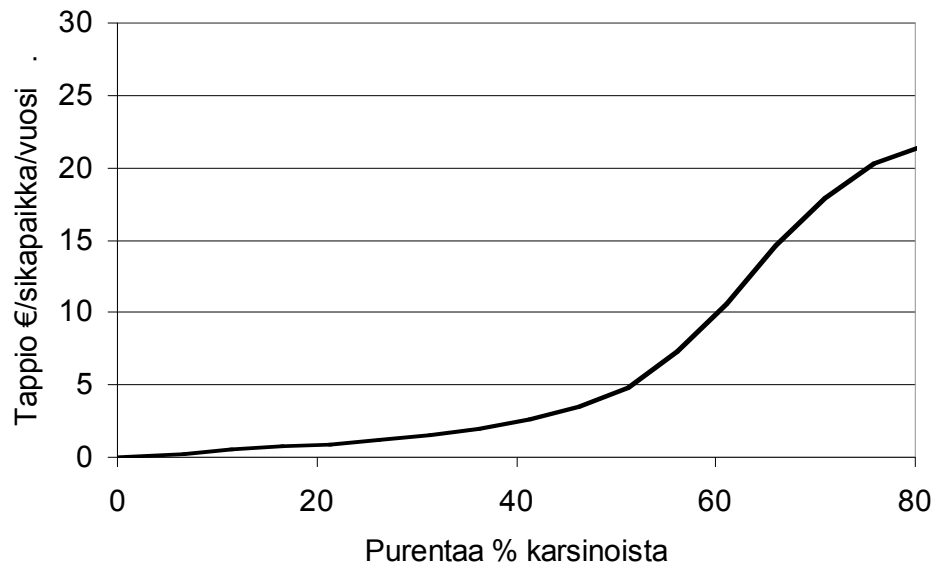

Kuva 3. Purentakarsinoiden esiintyvyyden (\%) ja karsinan sikapaikkaa kohti lasketun menetyksen (€/sikapaikka/vuosi) välinen simuloitu yhteys.

\section{Johtopäätökset}

Hännänpurenta vaikuttaa sikojen hyvinvointiin ja aiheuttaa kustannuksia. Olkien tarjoaminen virikkeeksi sioille on tutkimusten mukaan hyvä keino vähentää hännänpurentaa. Myös tuotantorakennuksen lämpötilaa ja ilmanvaihtoa sekä ruokintajärjestelmän toimintaa olisi syytä tarkkailla ja niiden puutteisiin reagoida. Hännänpurenta on monen tekijän summa, joten myös sen aiheuttamien tappioiden vähentämiseksi tehtävät toimenpiteet ovat moninaisia. 
Taipumus purra muita sikoja voi olla perinnöllistä ja sukupuolten välillä näyttää myös olevan eroja suhteessa hännänpurennan esiintyvyyteen. Lisäksi purrut siat kasvavat yleensä heikommin, niiden rehumuuntosuhde on heikompi ja niillä esiintyy enemmän tulehduksia sekä ruhohylkäyksiä kuin puremattomilla sioilla. Sikojen sairastuvuuden kohoaminen voi edelleen lisätä sikojen kuolleisuutta. Hännänpurenta voikin aiheuttaa merkittäviä tappioita, vaikka sitä esiintyisi harvakseltaan. Yksittäisen purentatapauksen aiheuttamat kustannukset voivat vaihdella muutamasta eurosta kymmeniin euroihin. Mittavimpia menetyksiä aiheuttavat muun muassa kokoruhohylkäykset ja tapaukset, joissa sika kuolee.

Tässä tutkimuksessa esitetyllä lähestymistavalla voidaan tarkastella hännänpurennan ja sen ennaltaehkäisyn taloudellista merkitystä sekä arvioida ennaltaehkäisyn ja hoidon taloudellisuutta. Jatkossa voidaan myös tarkastella, missä olosuhteissa ja miten paljon ennaltaehkäisyyn kannattaa panostaa.

\section{Kirjallisuus}

Bracke, M.B.M., Hulsegge, B., Keeling, L. \& Blokhuis, H.J. 2004. Decision support system with semantic model to assess the risk of tail biting in pigs 1. Modelling. Applied Animal Behaviour Science 87: 31-44.

Breuer, K., Sutcliffe, M.E.M., Mercer, J.T., Rance, K.A., O'Connell, N.E., Sneddon, I.A., Edwards, S.A. 2005. Heritability of clinical tail-biting and its relation to performance traits. Livestock Production Science 93: 87-94.

Day, J.E.L., Burfoot, A., Docking, C.M., Whittaker, X., Spoolder, H.A.M., Edwards, S.A. 2002. The effects of prior experience of straw and the level of straw provision on the behaviour of growing pigs. Applied Animal Behaviour Science 76: 189-202.

EFSA 2007. Scientific Report on the risks associated with tail biting in pigs and possible means to reduce the need for tail docking considering the different housing and husbandry systems. The EFSA Journal 611: 1-98 Fraser, A.F. and Broom, D.M. 1997. Farm animal behaviour and welfare. Farm animal behaviour and welfare. Wallingford, OX10 8DE UK, CAB International.

Guise, H.J. and Penny, R.H.C. 1998. Tail-biting and tail-docking in pigs. The Veterinary Record 142: 46.

Huey, R. J. 1996. Incidence, location and interrelationships between the sites of abscesses recorded in pigs at a bacon factory in Northern Ireland. The Veterinary Record 138: 511-514.

Hunter, E.J., Jones, T.A., Guise, H.J., Penny, R.H.C., Hoste, S. 2001. The relationship between tail biting in pigs, docking procedure and other management practices. Veterinary Journal 161: 72-79.

Kritas, S.K. and Morrison, R.B. 2007. Relationships between tail biting in pigs and disease lesions and condemnations at slaughter. The Veterinary Record 160: 149-152.

Lindertz, M. 2005. Hännänpurenta lihasikaloissa; altistavat tekijät ja ennaltaehkäisy. Eläinlääketietellinen tiedekunta.

Moinard, C., Mendl, M., Nicol, C.J., Green, L.E. 2003. A case control study of on-farm risk factors for tail biting in pigs. Applied Animal Behaviour Science 81: 333-355.

Niemi, J.K. 2006. Dynamic programming model for optimising feeding and slaughter decisions regarding fattening pigs. Agric. Food Sci. 15, Suppl. 1: 1-121. Saatavilla Internetissä: http://urn.fi/URN:ISBN:951-729-997-4. Niemi, J.K. \& Sevón-Aimonen, M-L. 2009. Economically optimal pig delivery scheduling and the design of meat pricing schemes when pig group is heterogeneous. 17th International Farm Management Congress - Plenary Papers, Applied Papers \& Poster Abstracts, Bloomington, Illinois, 19-24 July 2009. CD-rom. Saatavilla internetissä: http://www.ifmaonline.org/pages/congress.php

Paul, E. S., Moinard, C., Green, L. E. \& Mendl, M. 2007. Farmers' attitudes to methods for controlling tail biting in pigs. The Veterinary Record 160: 803-805.

Sambraus, H.H. 1985. Mouth-based anomalous syndromes. Ethology of farm animals. World animal science, Section A, 5: 391-472.

Wallgren, P., Lindahl, E. 1996. The influence of tail biting on performance of fattening pigs. Acta Veterinaria Scandinavica 37: 453-460.

Valros, A., Ahlstrom, S., Rintala, H., Hakkinen, T., Saloniemi, H. 2004. The prevalence of tail damage in slaughter pigs in Finland and associations to carcass condemnations. Acta Agriculturae Scandinavica Section AAnimal Science 54: 213-219.

Zonderland, J. J., Wolthuis-Fillerup, M., van Reenen, C.G., Bracke, M. B. M., Kemp, B., den Hartog., L. A, Spoolder, H. A. M. 2008. Prevention and treatment of tail biting in weaned piglets. Applied Animal Behaviour Science 110: 269-281. 